\title{
A BUSCA DA TUTELA DOS DIREITOS FUNDAMENTAIS NO ÂMBITO INTERNO E INTERNACIONAL
}

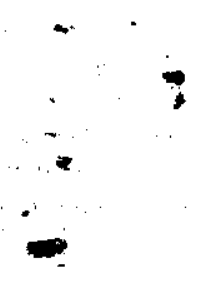

Revista Esmat, Palmas, Ano 3. n" 3. pag. 239 a 260 - jan/dez 2011 


\title{
A BUSCA DA TUTELA DOS DIREITOS FUNDAMENTAIS NO ÂMBITO INTERNO E INTERNACIONAL
}

\author{
Abilio Wolney Aires Neto ${ }^{19}$
}

\section{RESUMO:}

Este estudo, baseado em artigo do Prof. Dr. Dimas Pereira Duarte Júnior e no Cap. 9 da obra dos autores Guilherme C. Delgado e Mário Theodoro, objetiva analisar até onde chega a efetividade da tutela dos direitos fundamentais inerentes à pessoa humana no âmbito interno $\mathrm{e}$ internacional, numa perspectiva histórica, passando pela fase do pósSegunda Guerra até os dias atuais. Com efeito, no cenário mundial, colimando a Justiça Global, cada vez mais as Nações se unem aderindo a Pactos e Convenções, reconhecendo a autoridade de Organizações Intergovernamentais Internacionais, relativizando o próprio conceito de soberania, criando novos atores e sujeitos de direito a recorrerem a Instâncias supranacionais em busca da tutela dos direitos humanos. No âmbito interno, o Brasil avança no desafio da efetiva tutela de tais direitos, enquanto externamente cada vez mais entra no contexto das Nações Unidas, como fez ao reconhecer a autoridade do Tribunal Penal Internacional e ratificar, dentre outras, a Convenção Panamericana.

Palavras-chave: Tutela dos Direitos Fundamentais. Direitos Humanos. Brasil. Organizações Intergovernamentais Internacionais (OIGs).

\section{ABSTRACT:}

This study, based on article by Prof. Dr. Dimas Duarte Pereira Júnior and in Chapter 9 of the works of authors William C. Delgado and Mario Theodoro, aims to analyze how far the effectiveness of protection of

\footnotetext{
19 Professor de Direito Processual Civil na UniAnhanguera - Anápolis-GO. Especialista na área pela Universidade Federal de Goiás - UFG. Pós-graduado latu sensu pela Fundação Getúlio Vargas (MBA em Poder Judiciário). Mestrando em Direito pela Pontifícia Universidade Católica de Goiás. Autor de 10 livros, sendo dois jurídicos e os demais de história-literatura. Foi juiz presidente da $1^{\text {a }}$ Turma Recursal Mista dos Juizados do Estado. Ex-Promotor de Justiça e atual Juiz de Direito (1) da $9^{a}$ Vara Civel em Goiânia.
} 
fundamental rights inherent to the human person at ambit the domestic and international, in a historical perspective, going through the phase of post-Second World War until the present day. Indeed, on the world stage, objectiving Global Justice, more and more nations are adhering to Covenants and Conventions, acknowledging the authority of international intergovernmental organizations thereby questioning the very concept of sovereignty, creating new actors and subjects of rights resorting to in pursuit of supranational human rights protection. Domestically, Brazil advances in the challenge of effective protection of such rights, while externally increasingly enter the UN context, as it did on recognize the authority of the ICC and ratified, among others, the convention Pan American

Keywords: Enforcement of Fundamental Rights. Human Rights. Brazil. International Intergovernmental Organizations (IIOs).

\section{INTRODUÇÃO}

A questão dos direitos fundamentais inerentes à pessoa humana reponta como catálogo na Constituição da República, num elenco de magnitude histórica enquanto conquista na experiência dos séculos que precederam os avanços das civilizações. A liberdade e a dignidade, atributos maiores, surgem como o anelo das gentes para implementação pelo Estado, embutidos nos regimes de governo, mas desvelados nos sistemas, cooperativos ou competitivos, decorrentes da Lei Fundamental do País. Entre si, os direitos fundamentais devem ser interpretados de modo a coexistirem sem antinomia.

O aspecto histórico, o Código de Hamurabi (1700 a.C), que tinha a perspectiva da Lei de Talião, foi sucedido pela Antiguidade grega e romana, onde também não havia apreço 
pelos direitos fundamentais, não obstante os ideais de dignidade e igualdade, pois em verdade, livre era o homem que gozava da condição de se integrar com o Estado, participando das decisões políticas.

Com o advento da era cristã, os direitos fundamentais começaram a ganhar conformação, passando pelo período medieval, principalmente na Inglaterra, onde os direitos fundamentais significavam privilégios para alguns, portanto não universalizados.

Nos Estados Unidos, já na Declaração da Virgínia de 1776, havia um rol de direitos fundamentais.

A Revolução Francesa de 1789, com suas aspirações de liberdade, igualdade e fraternidade fixou marco rumo à universalização dos direitos fundamentais. Mas foi o texto da Declaração Universal dos Direitos Humanos, elaborado pelas Nações Unidas em 1948, que trouxe o intento de ampliar os direitos fundamentais ao plano da comunidade internacional. Contudo, diante da ausência de um sistema de restrições mútuas de âmbito internacional, esses "direitos", ao tempo de sua proclamação, ficaram no campo das idéias. Com efeito, denotava o anseio de um grupo de nações, no sentido de que aqueles mesmos direitos, que já existiam no contexto de Estados liberais democráticos, tivessem também aplicação no plano internacional, como prevê em seu art. 16: "Qualquer sociedade em que não esteja assegurada a garantia dos direitos fundamentais nem estabelecida a separação dos poderes não tem Constituição". 
No Brasil, a Constituição Federal de 1988 amplexou preceitos da Declaração dos Direitos do Homem e do Cidadão ao desdobrar em cinco capítulos os direitos fundamentais: "I Dos Direitos e Deveres Individuais e Coletivos; II - Dos Direitos Sociais; III - Da Nacionalidade; IV - Dos Direitos Políticos; V - Dos Partidos Políticos.” No início do art. $4^{\circ}$ do Preâmbulo, a Constituição afirma o seguinte: “A República Federativa do Brasil rege-se nas suas relações internacionais pelos seguintes princípios: (I) independência nacional; (II) prevalência dos direitos humanos; (III) autodeterminação dos povos; (IV) nãointervenção; (V) igualdade entre Estados.”

\section{DIMENSÃO DOS DIREITOS FUNDAMENTAIS, AS RELAÇÕES INTERNACIONAIS E A BUSCA DA TUTELA}

Cumpre observar que os direitos fundamentais tomam dimensão em momentos determinados da história. Poder-se-ia cogitar que a primeira dimensão foi influenciada pelos ideais do iluminismo e pelo jusnaturalismo dos séculos XVII e XVIII. Já os direitos de caráter social, econômico e cultural surgiram em segunda dimensão, no início do Século XX, com a necessária atuação positiva do Estado, propiciando aos cidadãos o direito à saúde, à segurança etc. Seriam de terceira dimensão os que dizem respeito à solidariedade e à fraternidade, como o direito ao meio ambiente e ao desenvolvimento, dentre outros, havendo ainda os que preconizam uma quarta dimensão de direitos, como o direito à democracia, ao pluralismo político e à informação, transitando 
para o regime tecnológico pós-moderno, a clonagem, o estudo das células tronco, o direito do embrião etc.

No âmbito interno, o desafio está na efetiva tutela judicial dos Direitos Fundamentais, em face da controvérsia acerca da necessidade de regulamentação de preceitos constitucionais e, em caso positivo, até onde o Congresso Nacional poderá estabelecer contornos a tais direitos. A par da questão, o Estado tem que lidar na realidade com a problemática de como por em prática um direito fundamental, diante da falta de recursos financeiros e estruturais do Estado Brasileiro.

O Supremo Tribunal Federal já se posicionou a respeito, como corte de superposição, sugerindo um debate que converge para assuntos como o cumprimento efetivo das decisões judiciais e seus impactos na efetivação dos direitos fundamentais, enquanto reflexos da atuação da Justiça na conformação da vida sócio-econômica do Estado.

O desafio da atualidade é buscar a tutela dos Direitos Fundamentais, inclusive numa análise dos Tratados e Convenções internacionais, cujos pactos representam um avanço para o reconhecimento de direitos fundamentais inerentes à pessoa humana, sem perder de vista a realidade de Nações hegemônicas no processo mundial, porquanto nas relações internacionais reina verdadeira assimetria de poder em termos axiológicos, onde a potência hegemônica sobrepõe às demais com seu poder tecnológico, bélico, sócio-econômico e cultural, condicionando ou inspirando opções com o condão do seu prestígio, aduzindo latente a sua faculdade de intimidar e coagir. 
No âmbito internacional, sempre que colidirem um direito humano e fundamental previsto no direito nacional e no direito internacional, levar-se-á em conta o preceito mais favorável aos direitos inerentes à pessoa. Essa idiossincrasia está ligada à questão das normas decorrentes de Tratados e Convenções internacionais, que dizem respeito a direitos humanos, que até certo ponto se equiparam a preceito constitucional interno, quando em sintonia.

Na perspectiva dos direitos e justiça globais, o trabalho de Immanuel Kant (Kant, 1970) parte de sua discussão sobre razão e seu uso público para apresentar a possibilidade de participação em um mundo cosmopolita, em contraposição à participação em uma sociedade civil. $\mathrm{O}$ direito cosmopolita de se apresentar e ser ouvido, através de comunidades políticas; a existência de uma comunidade universal e de uma cidadania universal são introduzidos pelo filósofo, o que atinge a questão da soberania interna e externa do Estado territorial, ante a idéia de uma sociedade internacional de Estados. A paz seria alcançada no momento em que todo os Estados fossem republicanos (Kant).

\section{JUSTIÇA GLOBAL. ORGANIZAÇÕES INTERGOVERNAMENTAIS INTERNACIONAIS}

A Declaração de Montreaux, por ocasião da Primeira Conferência do Movimento Mundial para um Governo Federal Mundial em 1947, e a campanha de Albert Einstein, por um governo mundial, são exemplos representativos. A preocupação 
com a ecologia, direitos humanos como cidadania, liberdade, proibição de tortura, trabalho escravo, convenção de direitos da criança, da mulher etc., que correspondem aos direitos de $1^{\circ}$ geração.

A proposta federalista de criação de um direito mundial (e não internacional), de cortes globais e de um aparato para garantir que essas leis sejam respeitadas está presente em movimentos sociais e textos acadêmicos. Os próprios documentos que definem os direitos humanos, desde a Declaração Universal de 1948, podem ser inseridos na história das idéias cosmopolitas. O regime de direitos humanos e a idéia de proteção do ecossistema partem do princípio do igualitarismo individualista. ADeclaração Universal dos Direitos Humanos de 1948, a Convenção sobre Tortura de 1984 ou o Estatuto da Corte Criminal Internacional, dentre outros, representam a presença, ainda que de difícil implementação, de princípios cosmopolitas. Esses convivem em constante tensão com a defesa de interesses e identidades particulares.

Finalmente, as organizações intergovernamentais internacionais e não-governamentais (OIGS e ONGIs) podem ser estudadas como parte de um movimento para formação de uma cidadania global.

As grandes guerras, o desenvolvimento econômico, as inovações tecnológicas e o próprio crescimento do número de Estados no sistema internacional, a partir da desagregação dos impérios, favoreceram um enorme crescimento do número de OIGs e ONGIs na segunda metade do séc. XX, já agora voltando 
os olhos para o problema do tráfico de drogas, das pandemias, dos recursos naturais não renováveis, da alocação de lixo nuclear, da proliferação de armas de destruição em massa, do aquecimento global e da regulação de mercados financeiros.

O final da Guerra Fria trouxe consigo o crescimento do número de países que compõem as OIGs e um otimismo inicial sobre o papel dessas, deflagrado com a intervenção no Iraque em 1991, sob a bandeira da ONU, e a Conferência sobre o Meio Ambiente no Rio de Janeiro em 1991. A ONU, a OTTAN e a Organização para Segurança e Cooperação na Europa, por exemplo, incorporaram um número grande de países sucessores da União Soviética.

As Organizações Intergovernamentais Internacionais (OIG), formadas por Estados, e as Organizações Não- Governamentais Internacionais (ONGI) são a forma mais institucionalizada de realizar a cooperação internacional. Hoje já são cerca de 238 OIGs e de 6.500 ONGIs. A maior parte foram criadas a partir da segunda metade do séc. XX.

A rede de organizações internacionais faz parte de um conjunto maior de instituições que garantem uma certa medida de governança global. Normas, regras, leis, procedimentos para a resolução de disputas, ajuda humanitária, a utilização de força militar, programas de assistência ao desenvolvimento, mecanismos para coleta de informações são algumas das práticas que produzem a governança global. As organizações são constituídas por aparatos burocráticos, têm orçamentos e estão alojadas em prédios. As OIGs empregam servidores públicos 
internacionais.

O sistema internacional, "desde as primeiras décadas do século $\mathrm{XX}$, tem sido caracterizado como sistema político anárquico. Contudo, a idéia é que a ausência de uma instância central geradora de normas legítimas e sancionadas, é um (denominador) comum mínimo. Nesse contexto, ao longo da história do sistema internacional moderno, inúmeros mecanismos de estabilização do sistema foram gerados. Os regimes internacionais, as alianças militares e a segurança coletiva estão diretamente associados ao processo de criação das OIGs. O balanço de poder, as zonas de influência, a estabilidade econômica, o Concerto de Estados, o direitos internacional, a cultura internacional são também muito significativos.

Arranjos ad hoc, ou seja, formas de cooperação voltadas para um fim específico em um tempo determinado, muitas vezes dão origem às OIGs. Quando o espaço institucional apropriado para uma negociação ou para a realização de um projeto específico não está disponível, os atores interessados geram um arranjo ad hoc, com uma ou várias reuniões de cúpula ou conferências internacionais. Em meados dos anos 70, o Grupo dos Sete surgiu, dessa maneira, em face dos problemas econômicos do período. Da mesma forma, a Conferência de Ottawa surgiu para eliminação de minas antipessoais em dezembro de 1997 e os tribunais, para julgamento de crimes contra a humanidade gerados pelo Conselho de Segurança da ONU para casos específicos. A experiência com cortes ad hoc para julgamento de crimes contra a humanidade foi fundamental 
para o processo de criação do Tribunal Penal Internacional em 2002, a cuja jurisdição o Brasil aderiu.

Já as alianças militares são coalizões de Estados formadas para enfrentar um inimigo real ou potencial. Elas geram a agregação de forças e de outros recursos para a defesa coletiva da coalizão. Elas podem ser ofensivas ou defensivas e ter maior ou menor grau de institucionalização. Nem todas as coalizões constituem uma aliança, às vezes elas são um arranjo ad hoc, como foi o caso da coalizão de países entre 19901991 para liberar o Kuwait da ocupação iraquiana. As alianças geram a formação de organizações, como foi o caso da OTAN (Organização do Tratado do Atlântico Norte), criada pelos EUA em 1949 para enfrentar a União Soviética.

Finalmente, as OIGs podem favorecer a legitimação " de normas e regras, ou seja, fazer a maior parte dos atores do sistema internacional acreditarem que elas devem ser respeitadas, gerando um sentimento de obrigação moral. Entretanto, as OIGs são dependentes dos Estados aderentes para adquirir legitimidade e enfrentam dificuldades específicas como a ausência de uma cultura comum robusta ou da possibilidade de impor decisões com o uso da força, com exceção de casos extremos.

Quanto ao processo decisório, as OIGs são, em geral, compostas por um corpo de representação ampla, como uma conferência ou assembléia, por um secretariado permanente. $\mathrm{O}$ voto, por maioria, o voto proporcional ou qualificado e a delegação do poder de veto a um grupo restrito de países são práticas amplamente disseminadas. As decisões são baseadas no 
consenso, ou seja, todos os países têm poder de veto, expressam o respeito pelo princípio da soberania - os Estados têm autoridade em última instância para decidir sobre questões domésticas e internacionais. O conceito de soberania cede face a produção de decisões que implicam a flexibilização desse mesmo conceito, embora a maior parte das decisões sejam recomendações, que somente serão implementadas se os Estados fizerem essa opção.

Organizações como o FMI e a UNDP (programa da ONU para o Desenvolvimento) adotam visões muito distintas quanto ao crescimento econômico e ao desenvolvimento. Algumas são compostas por apenas três membros, outras contam com quase totalidade dos Estados do sistema. Algumas têm funções bastante específicas e técnicas, outras lidam com a governança global de uma forma ampla. Algumas são regionais como a OEA (Organização dos Estados Americanos), ou ASEAN (Associação das Nações do Sudeste Asiático), outras são globais como OMC (Org. Mundial do Comércio) ou OMS (Organização Mundial da Saúde), UNICEF - Fundo da ONU para as crianças e OIT (Organização Internacional do Trabalho).

Quanto às organizações não-governamentais internacionais, são privadas e voluntárias, com membros individuais ou coletivos de diversos países. Algumas se voltam para causas como direitos humanos, paz ou a proteção ambiental. Em alguns casos, são redes ou federações nacionais como a Federação das Sociedades da Cruz Vermelha e do Crescente Vermelho ou Médicos Sem Fronteiras.

Em termos históricos, vale anotar que, a partir da década 
de 1970, o marxismo adquiriu um lugar como uma teoria de relações internacionais, com sua visão sistêmica, focalizada nos padrões de dominação, e a crença em uma mudança revolucionária, que trazem visão distinta das perspectivas liberal e realista, na discussão sobre a governança global, ante o domínio do pólo norte-americano, hegemônico no sistema, quando se deve avançar na idéia de um aparato de poder descentralizado e desterritorializado.

O FMI, a OMC (Organização Mundial do Comércio) ou o Banco Mundial são organizações nas quais a atuação de elites nacionais influem nas relações entre o norte desenvolvido e o sul menos desenvolvido.

\section{DIREITOS HUMANOS NO ÂMBITO DAS COMUNIDADES DE NAÇÕES}

Observa-se que, em termos de "organizações internacionais e regimes internacionais na construção do desenvolvimento sustentável e da governança global" destacouse a ONU, mormente no período pós-Guerra Fria (EUAURSS). O processo decisório no Conselho de Segurança foi descongelado, e a organização foi chamada a exercer um papel central na administração da segurança internacional. Aumentaram-se as agências funcionais, ressurgidas com maior ênfase em temas como: meio ambiente, assistência humanitária, combate às atividades criminais e epidemias, além da proteção aos direitos humanos. Soma-se a isso o interesse internacional 
no setor da saúde pública, o desenvolvimento tecnológico, o acesso à internet e a própria proliferação de organizações internacionais nesse quadro, não obstante as OIGs não terem poder nem autoridade para fazer as decisões serem cumpridas, pois os Estados optam por obedecer às regras e normas criadas, de acordo com seus interesses nacionais.

O Conselho e Assembléia da ONU, a Corte Internacional de Justiça, formada por 15 juízes eleitos para 9 anos, só podem se envolver em atividades no campo da segurança se todos os membros permanentes estiverem de acordo. $\mathrm{O}$ poder de veto funciona com um fusível e foi bastante usado na Guerra Fria EUA e URSS, depois Rússia. As resoluções da ONU não têm força militar. No caso da invasão do Kuwait pelo Iraque em 1990 a ONU reconheceu agressão, ruptura da paz e violação.

$\mathrm{O}$ princípio da não intervenção e a defesa dos direitos humanos parecem se conflitar, mas ganham sintonia com a visão cosmopolita de uma Justiça Global. O próprio debate contemporâneo sobre o conceito de justiça internacional tem a ver com a preservação da integridade dos respectivos cidadãos, mormente quando estes se encontrarem em circunstâncias perigosas fora de seus próprios territórios.

Cogita-se de um Estado de Direito em que ninguém estaria acima da lei, tanto no plano doméstico, quanto no plano internacional. Daí surgiu a Liga das Nações. O realismo assume que há, de fato, um conflito entre o auto-interesse (nacional) e a moralidade com as exigências da soberania nacional. Com efeito, não existe, no âmbito da moral, um tipo de autoridade análoga à 
autoridade que o Estado exerce no âmbito da política doméstica a figura hobbesiana do "soberano". Faltam sanções impostas por algum de tipo de instância superior, pois as que temos é de caráter informal, e não de caráter legal: desvantagens, por exemplo ao ser alijado de benefícios decorrentes da cooperação social, ostracismo social e desprezo. Surge, então, a idéia de um contrato social no âmbito das relações internacionais, com a indagação de ser ou não possível sancionar moralmente Estados como se faz a indivíduos, pois ainda falta instância superior suficiente no âmbito da "comunidade de nações". Melhor que instância seria uma instituição, diante da "anarquia" internacional. Bull, contudo, mostra, contra o realismo, ser possível falarmos em uma sociedade internacional, mesmo sem instância superior, por exemplo no campo da diplomacia e do comércio, ante o dilema dos sistemas hegemônicos (um ator), sistemas polarizados(dois atores) e sistemas em equilíbrio (mais de dois atores), em cujo contexto a preeminência militar, econômica e cultural gera a assimetria de poder, que desafia o princípio da legalidade, interna e internacionalmente, ante a ausência de uma autoridade suprema e de um lei formal e universalmente aceita que a todos subordina superando o problema da submissão de um Estado Membro a outro pela hegemonia.

Vale anotar que, no Pós-Segunda Guerra outros protagonistas surgiram, bem como novos sujeitos de direitos: organizaçõesinternacionaisintergovernamentais, frutodetratados ou convenções e a própria pessoa humana, hoje reconhecida como sujeito de direito internacional, embora diferenciado da 
posição dos Estados e das organizações internacionais. Ou seja, por força do sistema advindo Pós-Guerra, ancorado na DUDH (1948), deu-se origem ao Pacto Internacional sobre os Direitos Civis e Políticos de 1966 e seu Protocolo Facultativo de 1996 no âmbito das Nações Unidas, a Convenção internacional sobre a eliminação de todas as formas de discriminação racial de 1965 e a Convenção contra a Tortura e Outros Tratamentos ou Penas Cruéis de 1984, que deram capacidade postulatória junto a instâncias jurisdicionais internacionais, desde que esgotados os recursos internos dos Estados.

Com a criação do Tribunal Penal Internacional (Estatuto de Roma, 1998) para autores de crimes de guerra, genocídio, contra a humanidade e agressão, gerou-se um aparato normativo internacional no século XX, de modo a relativizar o conceito de soberania dos Estados, passando a divisar a cidadania na proteção seletiva aos direitos humanos. Apesar da DU de 1948 e do Pacto Sobre os Direitos Civis e Políticos e Pacto Sobre os Direitos Econômicos, Sociais e Culturais de 1966, tais direitos foram enunciados em tratados distintos ante a Guerra Fria: capitalismo-socialismo.

Por outro lado, o Tratado Constitutivo da Comunidade Européia - TCE (1957, art. 12 e 18), trouxe preceitos a garantir os trabalhadores (estudantes, jubilados e outros) à livre circulação dentro da União Européia, acesso ao emprego, estadia e à seguridade e assistência social, o que se consolidou na jurisprudência do Tribunal de Justiça das Comunidades Européias - TJCE (Luxemburgo), numa visão de "solidariedade 
transnacional", com proibição de discriminação no âmbito dos Estados Membros, não obstante o problema do "turismo social".

Quanto ao Brasil, ratificou em 1989 a Convenção Interamericana de 1985 para Prevenir e Punir a Tortura. No Pacto Sobre os Direitos Civis e Políticos - aos indivíduos, que passam a ter espaço no cenário da política doméstica dos Estados-Parte; no Pacto sobre os Direitos Econômicos, Sociais e Culturais, colimam-se os Estados.

\section{INTERNACIONAL ACCOUNTABILITY}

Foi ainda após a Segunda Guerra Mundial (Tribunal de Nuremberg, 1945-46) que surgiram mais tratados e convenções com força entre os Estados, cogitando-se dos mecanismos da accountability para uma poliarquia internacional, diante da mencionada assimetria de poder, com supremacia de um Estado sobre o outro, à míngua de autoridade legítima e eficaz capaz de impor uma ordem.

Na prática, a accountability é a situação em que "A reporta a B quando A é obrigado a prestar contas a B de suas ações e decisões, passadas ou futuras, para justificá-las e, em caso de eventual má-conduta, receber punições”. A forma embrionária de accountabilily remonta às antigas formas de organização estatal, v.g. na Grécia Antiga, modernamente ancorado nos escritos de Montesquieu, no Espírito das Leis e nos Federalistas, pressuposto do sistema dos Checks and Balances, nas relações internacionais, com nova roupagem recente, isto pelo fato do Pós-Segunda 
Guerra, cujas bases se assentam no direito internacional, em tratados e convenções com força entre os Estados. Não basta que tanto os protagonistas quanto os sujeitos sejam reconhecidos nos mecanismos da international accountability. São pressupostos seus a igualdade de poder entre representantes e representados, o império do princípio da legalidade e, ainda, o embate entre forças sociais e funções sociais, que vai redefinir o conceito de soberania e de cidadania.

\section{ATORES E SUJEITOS DE DIREITOS HUMANOS GLOBAIS}

Invocam-se as tradicionais teorias sobre os Atores e Sujeitos de direito internacional. Para Maquiavel, na Teoria realista, só a busca racional da expansão garante a sobrevivência do Estado, visto não haver garantia externa, o Estado garante-se a si próprio, o que move a guerra e a paz, a própria sobrevivência. Para a Teoria idealista - que tem origem nos escritos fundadores do ideário liberal, deve-se erigir uma autoridade comum para adotar normas de convivência para evitar, solucionar ou limitar os conflitos de interesses, e sancionar aqueles que rompam essas normas, já que os Estados são instituições abstratas, onde os efetivos atores são os indivíduos concretos que se relacionam, daí a anarquia da política internacional ser sobrepujada ante a racionalidade e a capacidade de cooperação.

$\mathrm{Na}$ perspectiva liberal, o Estado é o bem-estar e a prosperidade dos indivíduos. São protagonistas nas relações 
internacionais os Estados, Instituições, Pessoas, Organizações, Empresas, Meios de Comunicação e toda forma de associação com capacidade, não jurídica, mas de fato, de nela exercer influência. O sujeito de direito internacional é o protagonista ou agente sob os seguintes critérios: 1) a capacidade de produzir atos jurídicos internacionais; 2) a capacidade de verem-se imputados fatos ilícitos internacionais; 3) a capacidade de acesso aos procedimentos contenciosos internacionais; 4) a capacidade de os Estados tornarem-se membros e de participarem plenamente da vida das organizações internacionais intergovernamentais; e 5) a capacidade de estabelecer relações diplomáticas e consulares com outros Estados que são protagonistas e sujeito de direitos.

\section{CONCLUSÃO}

A gênese e o reconhecimento dos Direitos Humanos sinalizamparaumapoliarquia,mormenteapósa $2^{\mathrm{a}}$ GuerraMundial, com o advento de mais Organizações Intergovernamentais Internacionais, numa comunidades de nações, sobrepondose à utopia de uma Justiça Global. O estudo pretendeu acenar com tal possibilidade, situando os atores e sujeitos de direitos humanos na arena dos Estados-Parte que, ao firmarem Pactos ou Convenções se sujeitam às Cortes supranacionais, às quais prestam contas em função da international accountability. Fato é que, à medida que as democracias se consolidam no plano interno, com um Estado de Direito Constitucional, amplia-se a maravilhosa perspectiva de que a terra seja um dia um só País o 


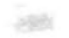

seres humanos seus cidadãos. ${ }^{1}$

\section{REFERÊNCIAS BIBLIOGRÁFICAS}

DUARTE JÚNIOR, Dimas Pereira. ACCOUNTABILITY E RELAÇÕES INTERNACIONAIS, artigo com a seguinte remissão bibliográfica:

ALBUQUERQUE, Jose A. G.. As relações internacionais contemporâneas: o mundo depois da guerra fria. Petropolis: Vozes, 2005.

BADIE, Bertrand. O fim dos territórios: ensaio sobre a desordem internacional e sobre a utilidade social do respeito. Tradução de Maria Jose Figueiredo. Lisboa: Instituto Piaget, 1995.

CAPELLA, Juan R. Fruto proibido: uma aproximação histórico-teórica ao estudo do direito e do Estado. Tradução de Gresiela Nunes da Rosa e Ledio Rosa de Andrade. Porto Alegre: Livraria do Advogado, 2002.

DAHL, Robert. Poliarquia : participação e oposição. Tradução de Celso Mauro Paciornik. São Paulo: Edusp, 1997.

$\overline{1}$ Frase em itálico de Bahá'u’lláh. 
ELSTER, Jon. Accountability in athenian politics in: Democracy, accountability an representation In: MANIN, B; PRZEWORSKI, A; STOKES, S. Cambridge: Cambridge University Press, s.d.

GROTIUS, H. Le droit de la guerre et de la paix. Trad. P. Pradier-Fodere. 1a ed. Paris: Presses Universitaires de France, 1999.

LESSA, Antonio C. História das relações internacionais: a pax britânica e o mundo do século XIX. Petrópolis: Vozes, 2005.

LOHBAUER, Christian. História das relações internacionais: o século XX: do declínio europeu à era global. Petrópolis: Vozes, 2005.

LOSANO, Mario G. Os grandes sistemas jurídicos: introdução aos sistemas jurídicos europeus e extra-europeus. Tradução de Marcela Varejão. São Paulo: Martins Fontes, 2007.

MADISON, John.; HAMILTON, A.; JAY, J. The federalists papers. Penguin Classics, 1987.

MAQUIAVEL, Niccolo. O príncipe (comentado por Napoleão Bonaparte). Tradução de Torrieri Guimaraes. São Paulo: Hemus, 1977.

MONTESQUIEU. O espírito das leis. Tradução de Fernando 
Henrique Cardoso e Leôncio Martins Rodrigues. Brasília: Editora UnB, 1995.

O'DONNELL, Guillermo. Accountability horizontal e novas poliarquias. Tradução de Clarice Cohn e Álvaro Augusto Comin. Lua Nova, n. 44, p. 27-54, 1998 . Poliarquias e a (in)efetividade da lei na América Latina.Tradução de Otacilio Nunes. Revista Novos Estudos, n.51, jul. 1998.

REIS, Henrique M. dos. Relações econômicas internacionais e direitos humanos. São Paulo: Quartier Latin, 2005.

SOARES, Guido F. S. Curso de Direito Internacional Público. 2.ed. São Paulo: Atlas, 2004. 